\title{
Potential Interactions of Remdesivir with Pulmonary Drugs: a Covid-19 Perspective
}

\author{
Zainab Gandhi $^{1}$ (D) $\cdot$ Zeeshan Mansuri $^{2} \cdot$ Snehal Bansod $^{3}$
}

Accepted: 13 August 2020 / Published online: 21 August 2020

(C) Springer Nature Switzerland AG 2020

\begin{abstract}
In this letter, we discuss the potential interactions of remdesivir, the newly approved Covid-19 drug with pulmonary medications. These interactions have been summarized keeping the busy clinician in mind. While remdesivir has proven to be a safe medication generally, we here have enlisted the potential interactions of remdesivir that a clinician needs to be mindful of while prescribing the medication.
\end{abstract}

Keywords Remdesivir $\cdot$ Drug interactions $\cdot$ Pulmonology

For coronavirus, there are various therapeutic regimens under trial. Remdesivir has shown promise in initial studies for treating COVID-19 [1]. The mechanism of action for remdesivir has been studied in vivo and in vitro [1]. It acts by delaying the chain termination of RNA synthesis through competing with ATP for incorporation [1]. It has been studied mainly for the Ebola virus and respiratory syncytial virus, but the broad mechanism of action can be helpful in the treatment for SARS-CoV2 [1]. With the use of precision medicine, we can prevent, mitigate, and provide personalized pharmacologic treatment to the patients $[2,3]$.

Remdesivir is a substrate of CYP 3A4, CYP 2D6, and CYP $2 \mathrm{C} 8$, and its metabolism is mediated by hydrolase activity $[4$, 5]. The potential co-administration of inhibitors can lead to a potential increase in its levels $[4,5]$. As remdesivir is a substrate of CYP 3A4, caution must be taken as it is co-administered

Zainab Gandhi and Zeeshan Mansuri share equal credit for primary authorship

This article is part of the Topical Collection on Covid-19

Zainab Gandhi

drzainabgandhi@gmail.com

1 Department of Infectious Diseases, University of California, San Francisco, CA, USA

2 Department of Psychiatry, Texas Tech University Health Science Center at Odessa/Permian Basin, Odessa, TX, USA

3 Department of Internal Medicine, St. John's Episcopal Hospital, Far Rockaway, New York, NY, USA with many drugs, including above, as CYP enzymes are involved in the metabolism of a wide range of medications. However, the initial data coming out shows no harmful effects of these drug-drug interactions, due to its rapid metabolism by hydrolase and esterase $[4,5]$. We conducted thorough search of Embase, PubMed, Scopus, PsycINFO, SciELO, and Web of Science. Since the drug is new and the information available is scarce, this commentary aims to review the potential interactions of remdesivir (Table 1).

\section{Pharmacodynamic Interactions}

Remdesivir has a low risk of significant pharmacodynamic interactions [6].

\section{Pharmacokinetic Interactions}

Steroids like dexamethasone and betamethasone induce CYP3A4 and thus will result in the rapid clearance of remdesivir [4]. Clinicians need to be cautious regarding this interaction. Rifampicin, rifabutin, and rifapentine strongly induce CYP3A4 enzyme [7]. These medications are used in the treatment of tuberculosis and leprosy. Co-administration of these medications with remdesivir can lead to rapid clearance and a significant decrease in remdesivir levels [6,7]. This combination should not be co-administered $[6,7]$. Bosentan is a drug primarily used in the treatment of pulmonary arterial hypertension. As it is mainly metabolized by CYP $3 \mathrm{~A} 4$ and 
Table 1 Drug interactions of remdesivir

\begin{tabular}{|c|c|c|}
\hline $\begin{array}{l}\text { Drug interacting } \\
\text { with remdesivir }\end{array}$ & Mechanism of action & Effect of drug interaction \\
\hline Metamizole & $\begin{array}{l}\text { Metamizole induces CYP3A4 and CYP2B6, and } \\
\text { remdesivir is a substrate for the same }\end{array}$ & $\begin{array}{l}\text { Leads to decreased levels of remdesivir by rapid clearance. There is no effect on } \\
\text { the metabolism of metamizole due to inhibition of CYP3A4 by remdesivir }\end{array}$ \\
\hline Rifampicin & Rifampicin strongly induces CYP3A4 and P-gp & $\begin{array}{l}\text { Leads to decreased levels of remdesivir by rapid clearance. There is no effect on } \\
\text { the metabolism of rifampicin }\end{array}$ \\
\hline Rifabutin & Rifabutin strongly induces CYP3A4 & $\begin{array}{l}\text { Leads to decreased levels of remdesivir by rapid clearance. There is no effect on } \\
\text { the metabolism of rifabutin }\end{array}$ \\
\hline Rifapentine & Rifapentine strongly induces CYP3A4 & $\begin{array}{l}\text { Leads to decreased levels of remdesivir by rapid clearance. There is no effect on } \\
\text { metabolism of rifapentine }\end{array}$ \\
\hline Carbamazepine & $\begin{array}{l}\text { Carbamazepine strongly induces CYP3A4 and } \\
\text { UGT2B7 }\end{array}$ & $\begin{array}{l}\text { Leads to decreased levels of remdesivir, no effect on carbamazepine as } \\
\text { remdesivir does not affect UGT's }\end{array}$ \\
\hline Phenytoin & Phenytoin strongly induces CYP3A4 & $\begin{array}{l}\text { Leads to decreased levels of remdesivir. There is no effect on phenytoin as } \\
\text { CYP2C9 metabolizes it }\end{array}$ \\
\hline Phenobarbitone & Phenobarbitone strongly induces CYP3A4 & $\begin{array}{l}\text { Leads to decreased levels of remdesivir. There is no effect on phenytoin as } \\
\text { CYP2C19, and CYP2C29 metabolize it }\end{array}$ \\
\hline Primidone & $\begin{array}{l}\text { Primidone is metabolized to phenobarbital and } \\
\text { thus induces CYP3A4 }\end{array}$ & $\begin{array}{l}\text { Leads to decreased levels of remdesivir. There is no effect on primidone by } \\
\text { inhibition of CYP3A4 by remdesivir as it is not metabolized by it }\end{array}$ \\
\hline St John's wort & St John's wort strongly induces CYP3A4 & $\begin{array}{l}\text { It can lead to decreased levels of remdesivir. No effect is observed on } \\
\text { metabolism of ST John's wort }\end{array}$ \\
\hline Dexamethasone & Dexamethasone strongly induces CYP3A4 & $\begin{array}{l}\text { It can lead to decreased levels of remdesivir by rapid clearance but no effect on } \\
\text { metabolism of dexamethasone }\end{array}$ \\
\hline Betamethasone & Betamethasone strongly induces CYP3A4 & $\begin{array}{l}\text { It can lead to decreased levels of remdesivir by rapid clearance but no effect on } \\
\text { metabolism of betamethasone }\end{array}$ \\
\hline
\end{tabular}

CYP 2C9, 4, 5, it has the potential of interaction with remdesivir. Although remdesivir causes inhibition of CYP 3A4, it is not expected to affect bosentan's metabolism. However, as bosentan is an inducer of CYP 3A4, it can potentially cause decreased levels of remdesivir [4]. Remdesivir does not interact with ambrisentan, epoprostenol, iloprost, macitentan, riociguat, selexipag, sildenafil, tadalafil, and treprostinil [6]. Remdesivir has no known interactions with any bronchodilators and beta-blockers and antivirals including oseltamivir [6]. Metamizole is a nonsteroidal antiinflammatory drug (NSAID) used for chronic pain management in many countries. Metamizole gets hydrolyzed to 4methylaminoantipyrine which is a substrate for CYP 3A4, $2 \mathrm{~B} 6,2 \mathrm{C} 8$, and $2 \mathrm{C} 9$. No effect is expected due to remdesivir as it inhibits CYP3A4. However, as metamizole induces CYP3A4 moderately and CYP2B6 strongly in vitro, it can lead to depleted levels of remdesivir [6].

In summary, since remdesivir is metabolized quickly, the risk of interactions is exceptionally low. As we deal with critically ill COVID-19 patients with underlying comorbidities, clinicians need to be careful about the co-administration of various drugs with remdesivir as listed above and keep an eye out for new data that comes out.

\section{Compliance with Ethical Standards}

Conflict of Interest The authors declare that they have no conflict of interest.
Ethical Approval Not required.

\section{References}

1. Tchesnokov E, et al. Mechanism of inhibition of Ebola virus RNAdependent RNA polymerase by remdesivir. Viruses. 2019;11(4): 326.

2. Crisci CD, Ardusso L, Mossuz A, Müller L. A precision medicine approach to SARS-CoV-2 pandemic management. Curr Treat Options Allergy. 2020:1-19. Advance online publication. https:// doi.org/10.1007/s40521-020-00258-8.

3. Di Sanzo M, Cipolloni L, Borro M, et al. Clinical applications of personalized medicine: a new paradigm and challenge. Curr Pharm Biotechnol. 2017;18(3):194-203. https://doi.org/10.2174/ 1389201018666170224105600.

4. McCreary EK, Pogue JM. Coronavirus disease 2019 treatment: a review of early and emerging options. Open Forum Infect Dis. 2020;7(4):ofaa105 PubMed.

5. Singh AK, et al. Remdesivir in COVID-19: a critical review of pharmacology, pre-clinical and clinical studies. Diabetes Metab Syndr Clin Res Rev. 2020;14(4):641-8.

6. Liverpool COVID-19 guidelines https://www.covid19druginteractions.org/checker accessed on May 16, 2020.

7. Zhou S-F. Drugs behave as substrates, inhibitors and inducers of human cytochrome P450 3A4. Curr Drug Metab. 2008;9(4):31022 PubMed.

Publisher's Note Springer Nature remains neutral with regard to jurisdictional claims in published maps and institutional affiliations. 